\title{
REPERTORIUM VAN TIJDSCHRIFTLITERATUUR OP HET GEBIED VAN ACCOUNTANCY EN BEDRIJFSHUISHOUDKUNDE
}

Verschänt maandelïks, behalve in augustus. Samengesteld door de Stichting voor Economisch Onderzoek der Universiteit van Amsterdam

\section{A. ACCOUNTANCY}

\section{HET ACCOUNTANTSBEROEP}

\section{The Accountant's Part in Computer Developments}

W right, M. G. - Of in de toekomst de accountant dan wel de ingenieur in voornaamste instantie vorm en inhoud zal geven aan de systemen voor de verwerking van gegevens, wordt mede bepaald door de mate waarin de accountant thans bereid is zich alsnog intensief met deze materie bezig te houden. Zo niet, dan bestaat het reële gevaar dat een gedeelte van de huidige taak van de accountant, i.c. de administratieve en informatieve organisatie, door de ingenieur en de wiskundige wordt overgenomen.

Dit gevaar klemt temeer omdat door de ontwikkeling van nieuwe programmeringstechnieken en de toepassing van computers, de verwerking van de gegevens meer en meer zal worden geïntegreerd zodat het gehele complex van handelingen kan worden teruggebracht tot een reeks van in elkaar grijpende programma's zonder tussenkomst van menselijke handelingen. Aan de hand van een schematisch voorbeeld geeft de schrijver aan hoe zo'n geïntegreerd systeem er in hoofdlijnen uitziet.

A II - 1 : III - 3

E $635.451:$ E $741.23:$ E 738.4

The Accountants Journal, januari 1964

\section{The Public Accountant's Contribution to Small Businesses}

B o y d, A. S. - Het is voor de kleinere accountantskantoren veelal moeilijk om de buiten het traditionele terrein liggende werkzaamheden, zoals belastingadviezen, kostprijsberekeningen, organisatieadviezen, te verrichten. Zij missen de daartoe vereiste gespecialiseerde kennis, noch kunnen zij zich veroorloven specialisten in dienst te nemen. Dientengevolge moeten zij soms hun cliënten naar de grotere kantoren verwijzen, dan wel trachten zij gezamenlijk gebruik te maken van gespecialiseerde kennis.

De schrijver pleit voor een wettelijke regeling, waarbij de plichten en bevoegdheden van de erkende openbare accountant worden vastgelegd. Een dergelijke regeling dient met name rekening te houden met de toenemende behoefte aan gespecialiseerde accountants. De schrijver meent derhalve dat men zich bij een nieuw te formeren structuur van het accountantsberoep moet richten naar die van andere vrije beroepen zoals medicus en jurist: aan de basis van de structuur de algemeen werkzame accountant, daarboven de door hen en uitsluitend via hen te consulteren onderscheidene specialisten.

A II -4

E $635.451:$ E 741.23

The Accountant, 25 januari 1964

\section{B. BEDRIJFSHUISHOUDKUNDE}

\section{a. ALGEMENE BEDRIJFSHUISHOUDKUNDE}

\section{WAARNEMINGSMIDDELEN}

\section{The Distintegration of an Information System}

Milroy, N. - De schrijver tracht een beeld te geven van de steeds groter wordende moeilijkheden bij de interne informatie in een groeiende onderneming. Daartoe gaat hij uit van het voorbeeld van een kleine onderneming en beschrijft in een zevental fasen hoe de door delegatie van werkzaamheden en door nieuwe bedrijfsactiviteiten toenemende behoefte aan informatie ontaardt in een volkomen ondoelmatig en zeer kostbaar systeem. Door 0.a. 
onvoldoende onderlinge afstemming en te late overdracht van gegevens gaan bedrijfsleiders over tot de inrichting van eigen informatiestelsels, welke duplicering de algemene chaos nog groter maakt. Het in dienst nemen resp. aanschaffen van steeds meer gespecialiseerde mensen en middelen doet het aantal elkaar kruisende informatiesystemen nog toenemen en leidt tenslotte tot een overdadige stroom van ongeselecteerde en onoverzichtelijke gegevens.

Een van de voornaamste oorzaken van de aldus ontstane verspilling is gelegen in de incidentele aanpassing, per groeifase, van de informatieprocedure aan de gewijzigde omstandigheden. De oplossing dient gezocht te worden in het tijdig invoeren van een geheel nieuw informatiesysteem, dat niet alleen „vandaag" maar ook „morgen" nog aan de gestelde eisen voldoet.

Ba III - 2

The Accountants' Magazine, januari 1964

E 73

\section{LEER VAN DE KOSTPRIJS EN DE PRIJSVORMING}

\section{Concepts of Cost}

M e p h a m, M. J., B. S c. - Terwijl de economist veelal uitgaat van het alternatieve kostenbegrip en mede met behulp hiervan het economisch gedrag van de subjecten tracht te verklaren, hanteert de accountant in hoofdzaak het kostenbegrip in de zin van gelduitgaven teneinde de bedrijfswinst van zijn cliënt te berekenen en tevens, door toerekening van de gemaakte uitgaven, een steunpunt te vinden voor de prijsstelling.

$\mathrm{Nu}$ recentelijk de opvatting meer opgeld doet dat verschillende kostenbegrippen gehanteerd dienen te worden al naar het beoogde doel, wordt het mogelijk tot een synthese te komen. Enerzijds wordt door de economist meer empirisch kostenonderzoek gepleegd, anderzijds verdiepen de accountants zich meer dan vroeger in de alternatieve mogelijkheden van de schaarse produktiemiddelen van hun cliënten. Mede door deze benadering kunnen lacunes worden aangevuld welke voortsproten uit de historische kostenconceptie, bv. met betrekking tot de waardeverandering van het geld, de rente van geïnvesteerd vermogen, de ondernemersbeloning.

Ba IV - 2a

The Accountant, 18 januari 1964

E 136.12

\section{De Nederlandse nationale rapporten voor het a.s. IFA-congres te Hamburg}

Sikk e l e r u s, M r. W. P. va n - De rapporten hebben betrekking op 1. internationale problemen met betrekking tot waardedaling, afschrijving en opwaardering van duurzame productiemiddelen voor de inkomstenbelasting en 2. afbakening van de bevoegdheid tot belastingheffing tussen het land van vestiging of woonplaats en andere landen met betrekking tot lichamen en haar aandeelhouders.

Het eerste rapport biedt voor de ingewijde weinig nieuws en blijft derhalve in dit artikel onbesproken. Het tweede onderwerp behoort tot het probleem van de internationale fiscale behandeling van de winst van lichamen. Verschillende aspecten hiervan zijn op voorgaande IFA-congressen behandeld. Internationale afbakening van bevoegdheid tot belastingheffing is een actueel probleem, ook in verband met recente Amerikaanse maatregelen. Het rapport geeft een hoofdindeling in a. belastingheffing van de vennootschap; b. belastingheffing van de aandeelhouders; c. belastingheffing over de grenzen heen.

De schrijver heeft critiek op de soms weinig overwogen formuleringen in het rapport, welke kunnen leiden tot misverstanden, vooral bij buitenlanders. De behandeling van de heffing over aanmerkelijk-belangwinsten is te simplistisch en schenkt geen aandacht aan de aparte positie van de kleine en middelgrote onderneming. De in het rapport genoemde bezwaren tegen eventuele belastingheffing door Nederland over de grenzen heen deelt de schrijver volledig.

Ba IV - 7

E 332.42

Weekblad voor fiscaal recht, 25 januari 1964

\section{Enige opmerkingen over het winststreven in de onpersoonlijke onderneming}

We r k e ma, D r. H. G. - De schrijver bestrijdt in de eerste plaats de opvatting van A. A. Alchian volgens welke de ondernemers niet naar winstmaximalisatie streven, omdat zij niet met zekerheid kunnen voorspellen welke gedragslijn tot maximale winsten zal leiden. Ook al zou een bewust uit de alternatieve doelstellingen geselecteerde maximand - de variabele waarvan men de waarde tracht te maximaliseren - ontbreken, dan nog impliceert een alternatieve gedragslijn, bv. imitatie of "trial and error", eveneens een te maximaliseren variabele. 
Naar aanleiding van een andere stelling, dat niet naar maximale winst, maar naar maximalisatie van het nut wordt gestreefd, merkt de schrijver op dat hier geen sprake behoeft te zijn van een tegenstelling. De veronderstelling van een winstmaximalisatie houdt in dat het nut van de besluitvormers een monotoon toenemende functie is van de behaalde, resp. te verwachten winst. In verband hiermede gaat de schrijver nader in op de verklaring van de motieven voor winstmaximalisatie. Hij stelt daarbij o.a. dat de continuïteitsgedachte zowel van toepassing is op de persoonlijke als op de onpersoonlijke onderneming.

Ba IV - 8

Maandblad voor Accountancy en Bedrïfshuishoudkunde, februari 1964

E 251.3

\section{LEER VAN DE FINANCIERING}

\section{Investment Policy and Management}

M o y e r, F. W. - Indien de leiding van een onderneming overweegt een overschot aan kasmiddelen te beleggen in plaats van aan te houden in een bankdeposito, dient allereerst de toekomstige behoefte, op korte en op langere termijn, aan kasmiddelen te worden berekend. Voor een keuze uit de beleggingsmogelijkheden zijn vervolgens onder meer bepalend de liquiditeit en de opbrengst van de beleggingstypen. De schrijver onderscheidt drie typen, variërend van direct opzegbare met een lage opbrengst tot die met een relatief hoge opbrengst en een looptijd van twee of meer jaar. Voor elk van deze groepen kan men de opbrengst vergelijken met die van staatspapieren met een corresponderende looptijd, zoals schatkistpapier en staatsobligaties.

De schrijver besteedt ook enige aandacht aan de risico's, verbonden aan buitenlandse fondsen, in verband met onzekere wisselkoersen, alsmede aan de mogelijkheid van belegging in door de onderneming zelf uitgegeven waardepapieren. Het getuigt van wijs beleid indien de hoogste leiding van de onderneming haar greep op de beleggingspolitiek behoudt door terzake $\mathrm{k}$ walitatieve en $\mathrm{kwantitatieve} \mathrm{grenzen} \mathrm{voor} \mathrm{de} \mathrm{beleggingsspecialist}$ vast te stellen.

$\mathrm{Ba} \mathrm{V}-2$

E 324.22 : E 343

Financial Executive, januari 1964

\section{Commercial Financing: An Economic Tool}

P a l a ma ra, F. J. - Indien een onderneming in haar vermogensbehoefte niet kan of wil voorzien door het uitgeven van aandelen, bestaan er naast het normale bankcrediet nog andere mogelijkheden. De schrijver wijdt een korte beschouwing aan de volgende vormen: 1. een lening van een financieringsmaatschappij, waarbij de onderneming haar vorderingen, voorraden en/of duurzame activa tot zekerheid doet strekken; 2. "factoring", dat is de overdracht van vorderingen, waarbij de koper tegen berekening van commissie en rente de financierings- en de incasso-functie overneemt; 3 . de koop op afbetaling van produktiemiddelen; 4. de huur van produktiemiddelen; 5. de herdiscontering, een vorm van lening aan op het terrein van het consumentencrediet werkzame financieringsmaatschappijen. De schrijver geeft een summiere behandeling van deze financieringsvormen in verband met de feitelijke vermogenspositie van de zich uitbreidende ondernemingen.

$\mathrm{Ba} \mathrm{V}-5$

Financial Executive, januari 1964

E 325.31

\section{Huur als financieringsvorm}

$\mathrm{Sch}$ eff e r, Prof. Dr. C. F. - Voor de vergelijking van financiële huurovereenkomsten met andere financieringsmethoden dient veelal een andere analyse te worden toegepast dan met betrekking tot de operationele huurbeslissing. Bij de laatste beslissing is veelal geen sprake van een keuzeprobleem omdat geen alternatieve mogelijkheden beschikbzar zijn. Men huurt om operationele redenen, bv. omdat aankoop van het object niet mogelijk is ofwel omdat men slechts gedurende zeér korte tijd over het object bchoeft te beschikken. De opcrationele huurbeslissing kan dan ook als cen investeringsbeslissing worden beschouwd. De financiële huurovereenkomst betreft daarentegen een financieringsbeslissing, die overigens simultaan met de investeringsbeslissing wordt genomen. De financiële huur geldt als alternatief van enigerlei andere financieringswijze, bv. van de koop op afbetaling. De vraag, welke financieringswijze voor de onderneming het voordeligst kan worden geacht hangt af van de concrcte situatic waarin de onderneming zich bevindt. Vast staat, dat de financiële huur uitkomst kan bieden in gevallen, waarin de onderneming, hoewcl voldoende kapitaalkrachtig, om bepaalde redenen geen toegang heeft tot andere declmarkten van de kapitaalmarkt. Wordt dezc financieringsvorm gekozen, dan staat de onderneming poor vaste toekomstige betalingen die het karakter van vaststaande 
verplichtingen dragen. Deze betalingen staan los van de uit de investering te verwachten inkomsten en mogen daarop niet zonder meer in mindering worden gebracht. Immers, de kapitaalwaarde van het investeringsproject en de kostenwaarde van de financieringsvormen zijn onafhankelijke beslissingsvariabelen.

$\mathrm{Ba} \mathrm{V}-5 \mathrm{~d}$

E 325.312

Maandschrift Economie, januari 1964

\section{LEER VAN DE ORGANISATIE}

\section{Continuïteit van de onderneming}

In een gecombineerd januari/februarinummer wordt een aantal essentiële vraagstukken behandeld, welke samenhangen met continuïteit en discontinuïteit op het gebied van de economie, het civiel en het fiscaal recht. Naast de bijdragen van Prof. Kleerekoper en Dr. Misset, elders in dit repertorium weergegeven, schreef Ir. M. Lopes Cardozo over wetenschappelijk onderzoek en continuïteit van de onderneming, Dr. J. P. I. van der Wilde over het midden- en kleinbedrijf, Dr. D. Horringa over familiale opvolging en Mr. H. H. Nauta over de familie-onderneming.

Op het gebied van het fiscaal recht behandelde Dr. L. Lancée het fiscale winstbegrip, J. Spaanstra de belastingheffing bij de eenmans-onderneming en de personenassociatie, Dr. J. H. Christiaanse de fiscale aspecten bij de naamloze vennootschappen en C. van Soest de belastingbesparing ter wille van de continuïteit. Tenslotte werden enkele civielrechtelijke bijdragen geschreven door Mr. Dr. H. F. A. Völlmar en Prof. Mr. J. M. Polak, de laatste over de oprichting van stichtingen in verband met de continuïteit van de onderneming.

Ba VI - 2

E 612.12

Tijdschrift voor Vennootschappen, Verenigingen en Stichtingen, januarilfebruari 1964

\section{Wet van de continuïteit}

K l e er ek oper, Prof. D r. S. - Voor een goed begrip van het economisch continuïteitsprincipe dient men terug te gaan tot het verschijnsel van de moderne arbeids- of produktieverdeling, waarbij de grenzen van de gezinshuishouding worden overschreden. Ten onrechte wordt veelal gestcld dat de arbeidsverdeling aan het begin van de organisatie van het produktieproces staat. Aan haar zijn voorafgegaan primaire omwegproduktie en arbeidsvereniging, beide directe consequenties van het economisch motief hetwelk tevens geleid heeft tot het onafscheidelijk met de arbeidsverdeling verbonden verschijnsel van de arbeidsverbijzondering, waarbij sprake is van een zekere dialectische werking.

Alvorens nu een producent zal deelnemen aan het produktieproces, wenst hij de redelijke zekerheid dat in het geschetste complex van krachten, geconcentreerd rond arbeidsverdeling en omwegproduktie, een zekere continuïteit aanwezig is. De continuïteit is dus enerzijds voorwaarde voor, anderzijds gevolg van de arbeidsverdeling en de omwegproduktie.

De aldus geldende wet van de continuïteit manifesteert zich als een wet der traagheid welke steeds weer wordt doorbroken door zelf in het leven geroepen tegenkrachten; deze afwisseling van continuïteit en discontinuïteit representeert de economische ontwikkeling. De schrijver merkt tenslotte op dat het niet-monotone karakter van de dialectische werking van continuïteitshandhaving en -doorbreking een nieuwe problematiek heeft veroorzaakt. Men ziet $\mathrm{nl}$. in nieuwe kapitaalvorming - continuïteitsdoorbreking - alleen maar heil en beschouwt bv. investeringsbeperking eigenlijk als abnormaal. Als uitweg uit deze problematiek geldt geen algemeenheid, doch hangt alles af van bijzondere omstandigheden, welke het meest gewenste evenwicht bepalen.

Ba VI - 2

E 612.12

Tïdschrift voor Vennootschappen, Verenigingen en Stichtingen, januari/februari 1964

\section{Onzekerheid en continuïteit}

$\mathrm{M}$ is set, Dr. H. A. J. F. - De uit de wet van de continuïteit volgende bedrijfseconomische norm, volgens welke de bedrijfsleiding eerst tot verbreking van die continuïteit mag overgaan indien de nadelen van de bestaande produktie-organisatie de voordelen ervan overtreffen, hangt bij praktische toepassing nauw samen met het bestaan van een reeks van onzekerheden, welke een nauwkeurige afweging van voor-en nadelen van bv. een investering uitsluiten. De schrijver noemt o.a. technische vooruitgang, produktontwikkeling, marktverhoudingen, overheidspolitiek, technologische werkloosheid door mechanisering en automatisering. De bedrijfsleiding kan haar inzicht in deze onzekere factoren vergroten alsmede haar besluitvorming betreffende continuïteitshandhaving of -verbreking verbeteren door gebruik te maken van de in de hiërarchische structuur aanwezige deskundigheden, elk op een eigen onzekerheidsniveau. $\mathrm{Zij}$ kan tevens door passend onder- 
zoek naar de oorzaken van afzet-en prijswisselingen en van produkt- en procesontwikkeling haar kennis vergroten ten aanzien van omvang en spreiding van de winsten bij verschillende technische en economische ontwikkelingen. De schrijver spitst zijn betoog toe op de zg. duurzame produktiemiddelen. Het voordeel van de beschreven oorzakenanalyse is dat zij in tegenstelling tot de $\mathrm{zg}$. pay off-methode, de verschillende factoren in onderling verband plaatst en hun relatieve betekenis onderscheidt.

Ba VI - 2

E 612.12 : E 252.4

Tijdschrift voor Vennootschappen, Verenigingen en Stichtingen, januari/februari 1964

\section{Der Mann am Steuer}

A t teslander, P. - De schrijver tracht, mede aan de hand van een literatuurstudie, een antwoord te geven op de vraag of er "geboren" leiders zijn, dan wel of de vereiste eigenschappen kunnen worden geleerd. De schrijver wijst in dit verband o.a. op de onderzoekingen door de Amerikaanse school van Lewin.

Ten onrechte wordt het begrip leiding veelal op een lijn gesteld met de in een organisatie vastgelegde taken van de dirigerende en controlerende "leidende" functies. Men dient alleen dan van leiding te spreken indien uit het handelen in een bepaalde groep een structuurwijziging van het groepssysteem voortvloeit. Aldus gesteld kan geen sprake zijn van permanente leiding, terwijl bovendien een zodanige leider op elk niveau in de hiërarchie kan voorkomen. De schrijver verwijst o.a. naar Schumpeter die slechts dan van een ondernemer spreekt indien en voor zover deze een wezenlijke leidersfunctie uitoefent.

De in de aanvang van het artikel gestelde vraag wordt ontkennend beantwoord. Geboren leiders bestaan evenmin als geboren groepen en kunnen ook niet worden opgeleid; leiding komt voort uit de voortdurende handelingen tussen de leden van een groep, in een vorm welke wordt bepaald door de geldende groepsnormen en -structuur. Slechts de voorwaarden welke tot een effectieve leiding bijdragen, kunnen worden onderwezen en geleerd, zoals bv. reeds sedert jaren plaats vindt aan de Harvard Graduate School of Business Administration.

$\mathrm{Ba}$ VI - 16

E 641.22

Industrielle Organisation, 1964 nr. 1

\section{Managerial Discretion and Business Behavior}

Willia mson, O. E. - De schrijver onderzoekt met behulp van de modeltechniek in welke mate en op welke wijze vrijheid van handclen van de leiding het doel van het ondernemen beïnvloedt. Gesteld wordt dat naast het winstdoel zekere andere strevingen als macht, zekerheid en vooral prestige de allocatie der middelen beïnvloeden. Deze veronderstellingen vergelijkt de schrijver met die van de maximale winst-hypothese. Zich vooral richtend op het grootbedrijf wenst de schrijver het bewijs te leveren aan de hand van de praktijk. Gebaseerd op het samengaan van eigen belang en rationeel handelen, wordt voorgesteld een algemene benadering ter introductie van leidingsdoeleinden in een bedrijfstheorie. Het begrip ,,uitgave-voorkeur" verschaft de essentiële verbinding ter relatering van de beleidsdoeleinden aan operationeel gedrag. Het bestuursmodel volgt de meeste veronderstellingen der klassieke theorie van de winst-maximalisatie, echter ten aanzien van de effecten van sommige belastingen (o.a. de winstbelasting) verschaft het model antwoorden, strijdig met de klassieke theorie. Het geleverde bewijs is meer suggestief dan definitief. Hoewel niet sterk genoeg om een tegenstelling te scheppen tussen de nuts- en winstmaximalisatie, geeft het bestuursmodel het bewijs dat een belangrijk deel der feitelijke winsten intern wordt weggezogen. Dit doet de vraag rijzen of studies van monopoloide krachten, gebaseerd op vermelde winsten wel voorzien in een betrouwbare beoordeling van de effecten van het monopolie. Een continu onderzoek van de effecten van vrijheid van handelen op het gedrag van de leiding lijkt gewettigd. De econoom kan de niet-geldelijke motieven met een economische inhoud verschaffen. Dat het onderzoek nog niet ver gevorderd is, wijt de schrijver aan het feit dat de econoom deze conceptie niet serieus genoeg beziet.

Ba VI - 16

E 133.3

The American Economic Review, december 1963

\section{The case against the economic batch quantity}

B u r bidge, J. - De schrijver keert zich in dit artikel tegen de toepassing van de beginselen van de optimale seriegrootte, waarbij de laagste totale kosten, opgebouwd uit die welke rechtstreeks variëren met het aantal series en uit die welke rechtstreeks samenhangen met de seriegrootte, bepalend zijn voor de optimumpositie. Mede aan de hand van schematische voorstellingen tracht hij aan te tonen dat de totale produktiekosten volgens dit systeem niet of nauwelijks kunnen worden gedrukt, terwijl operationeel onderzoek en 
computerberekeningen nodig zijn om te trachten de produktseries in het produktieschema op elkaar af te stemmen.

Betere en minder gecompliceerde mogelijkheden biedt z.i. het voor produktie in het groot toegepaste principe van de lijnproduktie, waarbij alle produktielijnen tezelfdertijd even grote series van dezelfde onderdelen maken, welke in de volgende produktieperiode in de assemblagelijn kunnen worden gezet. Volgens de schrijver zijn op deze wijze belangrijke kostenbesparingen, met name in de voorraadkosten, mogelijk.

Ba VI - 19

E 641.231 .2 : E 136.352 .13

The Manager, januari 1964

\section{LEER VAN DE ARBEIDSVOORWAARDEN}

\section{De collectieve arbeidsovereenkomst}

Ter herdenking van het feit, dat op 5 januari 1914 de eerste C.A.O. in de typografie in werking trad, is het januarinummer van dit tijdschrift geheel gewijd aan de collectieve arbeidsovereenkomst. Onder meer komen bijdragen voor van Prof. Mr. W. C. L. van der Grinten over de publiekrechtelijke bedrijfsorganisatie, van Mr. C. J. Nierstrasz in verband met het gewijzigde Buitengewoon Besluit Arbeidsverhoudingen, van Mr. B. S. Frenkel over Secundaire arbeidsvoorwaarden, van Mr. C. A. Terwee-van Hilten over het stakingsrecht en van Prof. Mr. M. G. Levenbach die enkele rechtsvergelijkende opmerkingen maakt. Tevens is opgenomen een statistisch overzicht van de ontwikkeling van het aantal C.A.O.'s in Nederland vóór 1940 en na 1945 tot en met 1962.

Ba VII - 4

E 225.521.2

Sociaal Maandblad Arbeid, 5 januari 1964

\section{Psychological Industrial Testing}

In een discussie tussen Prof. Dr. B. Balinsky, hoogleraar voor industriële psychologie te New York, en M. L. Gross, een man uit het bedrijfsleven en schrijver van "The Brain Watchers", stelt de eerstgenoemde dat de psychologische test het mogelijk maakt een objectieve beschrijving te geven van de eigenschappen en (potentiële) bekwaamheden van de individuele sollicitant, hetzij in verband met de openstaande functie, hetzij voor andere taken. Balinsky acht het geen bezwaar dat de werkgever tevens opdracht geeft voor dergelijk onderzoek, omdat de beroepsethiek van de psycholoog waakt tegen eventuele benadeling van de onderzochte persoon.

Gross is een aperte tegenstander van psychologisch onderzoek ter beoordeling van sollicitanten. Zijn voornaamste argumenten zijn: 1. deze wetenschap is nog niet voldoende ontwikkeld, haar hulpmiddelen zijn ontoereikend voor een verantwoorde karakterbeschrijving; 2. noch de bedrijfsmensen, noch de psychologen kennen de criteria waaraan een (betere) functionaris moet voldoen; 3. een bedrijfspsychologisch onderzoek doet niet meer dan het ryperen van een mens op een bepaald moment in zijn carrière. Als een grondslag voor personeelsbeleid is dit onvoldoende en kan zowel het bedrijf als de onderzochte er schade van ondervinden. De mens ontwikkelt zich voortdurend, over de aard en richting van zijn carrière valt niets te voorspellen. Gross meent dat de enige juiste manier om iemand objectief te benaderen is, hem op de desbetreffende plaats te stellen en zijn prestaties te volgen.

Ba VII - 5

E 641.212.301

Factory, januari 1964

\section{Management Education}

Robinson, O. W. - De invloed van de wetenschappelijke en technische ontwikkeling op de technische en administratieve organisatie, de zich voortdurend wijzigende economische en sociale verhoudingen alsmede de hieruit voortvloeiende verandering in de aard der beleidswerkzaamheden, maken de vorming van bedrijfsleiders tot een der voornaamste problemen van deze tijd. De opleiding en voortgezette scholing van bedrijfskader zal een integraal deel van het personeelsbeleid moeten vormen.

Daarnaast zullen post-universitaire leergangen moeten worden ingesteld om de bedrijfsleiders op de hoogte te brengen van nieuwe ontwikkelingen en vooral om hun begrensde blik te verruimen. Tenslotte zullen ook de beroepsorganisaties zich, in samenwerking met de universiteiten en het bedrijfsleven, met deze kwestie moeten bezighouden. De schrijver nocmt als voorbeelden van onderzock naar en uitwerking van toegepast bedrijfskaderonderwijs, de activiteiten van de Ford Foundation en de Carnegie Corporation.

$\mathrm{Ba}$ VII -7

The Canadian Chartered Accountant, januari 1964

E 641.212.461 